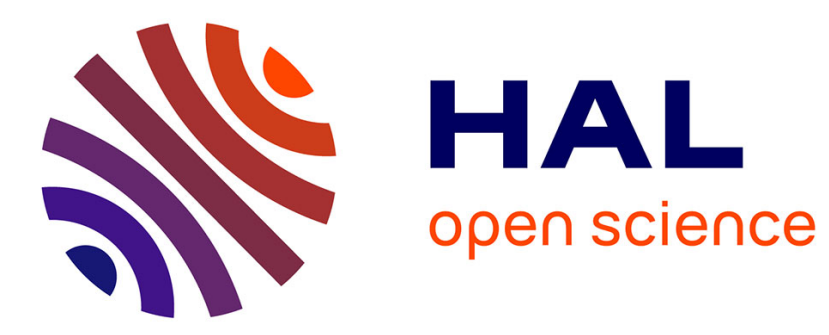

\title{
Energy transfer in near-resonant molecular collisions from diatomic to symmetric top molecules
}

\author{
L. Torchin
}

\section{To cite this version:}

L. Torchin. Energy transfer in near-resonant molecular collisions from diatomic to symmetric top molecules. Journal de Physique Lettres, 1981, 42 (15), pp.357-360. 10.1051/jphyslet:019810042015035700 . jpa-00231946

\section{HAL Id: jpa-00231946 https://hal.science/jpa-00231946}

Submitted on 1 Jan 1981

HAL is a multi-disciplinary open access archive for the deposit and dissemination of scientific research documents, whether they are published or not. The documents may come from teaching and research institutions in France or abroad, or from public or private research centers.
L'archive ouverte pluridisciplinaire HAL, est destinée au dépôt et à la diffusion de documents scientifiques de niveau recherche, publiés ou non, émanant des établissements d'enseignement et de recherche français ou étrangers, des laboratoires publics ou privés. 


\title{
Energy transfer in near-resonant molecular collisions from diatomic to symmetric top molecules
}

\author{
L. Torchin \\ Laboratoires de Marcoussis, Centre de Recherches de la C.G.E., Division Lasers, 91460 Marcoussis, France
}

(Reçu le 26 mars 1981, révisé le 5 mai, accepté le 9 juin 1981)

\begin{abstract}
Résumé. - Nous avons étendu une théorie du transfert d'énergie vibrationnelle, basée sur l'interaction multipolaire à grande distance, au cas où l'une des molécules est une toupie symétrique. Nous avons calculé la valeur de la probabilité d'échange en fonction de la température pour cinq réactions d'échange entre $\mathrm{D}_{2}(v=1)$ et $\mathrm{CH}_{3} \mathrm{Cl}$, $\mathrm{CH}_{3} \mathrm{CCH}$ ou $\mathrm{NH}_{3}$. Les valeurs obtenues sont assez faibles, à cause du grand nombre de niveaux de rotation dans les toupies symétriques.
\end{abstract}

\begin{abstract}
A theory of vibrational energy transfer using long-range multipolar interaction has been extended to the case of a transfer between a diatomic and a symmetric top molecule. Energy transfer probabilities versus temperature were calculated for five energy-exchange reactions between $\mathrm{D}_{2}(v=1)$ and $\mathrm{CH}_{3} \mathrm{Cl}, \mathrm{CH}_{3} \mathrm{CCH}$ or $\mathrm{NH}_{3}$. Due to the great number of rotational levels in symmetric top molecules, the values obtained are rather low.
\end{abstract}

1. Introduction. - Up to now, vibration-to-vibration (V-V) energy transfer calculations based on long-range interaction forces have been mainly applied to the case of energy transfer between diatomic or linear polyatomic molecules. The theory of these calculations was first derived by Sharma and Brau [1, 2]. Assuming long-range multipolar interaction, non or weakly polar molecules and near-resonant collisions, these calculations have given results which are most often in rather good agreement with experiment below $1000 \mathrm{~K}$. To our knowledge Preses and Flynn [3] mentioned the only application of Sharma's theory to V-V energy transfer reaetions involving symmetric top molecules, but their formalism was not developed. The present paper extends Sharma's theory for energy exchange reactions between a diatomic and a symmetric top molecule.

2. Theory. - Consider the binary collision of energy defect $\Delta E$ :

$\dot{\mathrm{D}}_{2}\left(v=n_{2}+1, J_{2}, M_{2}\right)+\mathrm{X}\left(v_{i}=n_{1}, J_{1}, K_{1}, M_{1}\right) \leftrightarrows \mathrm{D}_{2}\left(v=n_{2}, J_{2}^{\prime}, M_{2}^{\prime}\right)+\mathrm{X}\left(v_{i}=n_{1}+1, J_{1}^{\prime}, K_{1}^{\prime}, M_{1}^{\prime}\right)+\Delta E$

$\mathrm{D}_{2}$ being a diatomic molecule, and $\mathrm{X}$ a symmetric top. $J_{1}, K_{1}, M_{1}, J_{2}, M_{2}$ are the initial rotational quantum numbers, $J_{1}^{\prime}, K_{1}^{\prime}, M_{1}^{\prime}, J_{2}^{\prime}, M_{2}^{\prime}$ the final ones and $n_{1}$ and $n_{2}$ the vibrational quantum numbers of both molecules. Using first-order perturbation theory, the probability $P$ of such a collision is given by :

$$
P_{J_{1} J_{2} K_{1} M_{1} M_{2}}^{J_{1}^{\prime} J_{i}^{\prime} K_{1}^{\prime} M_{1}^{\prime} M_{2}^{\prime}}=\frac{1}{\hbar^{2}}\left|\int_{-\infty}^{+\infty} \mathrm{e}^{i \omega t}\left\langle n_{2} n_{1}+1 J_{1}^{\prime} J_{2}^{\prime} K_{1}^{\prime} M_{1}^{\prime} M_{2}^{\prime}|V(t)| n_{2}+1 n_{1} J_{1} J_{2} K_{1} M_{1} M_{2}\right\rangle \mathrm{d} t\right|^{2}
$$

where $\omega=\Delta E / \hbar$, and $V(t)$ is the intermolecular potential. $V(t)$ can be expanded in terms of multipole series [4,5] :

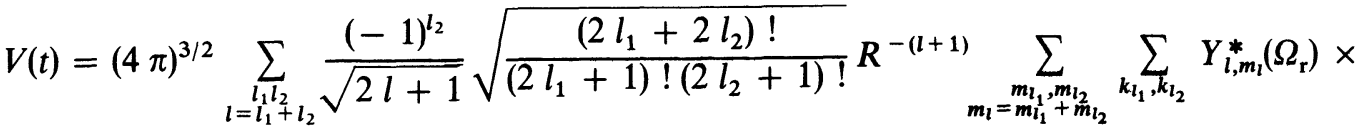

$$
\begin{aligned}
& \times C\left(l_{1} l_{2} l \mid m_{l_{1}} m_{l_{2}} m_{l}\right) D_{m_{l_{1}}, k_{1}}^{l_{1}}\left(\Omega_{1}\right) D_{m_{l_{2}}, k_{2}}^{l_{2}}\left(\Omega_{2}\right) \bar{Q}_{l_{1}, k_{l_{1}}}^{(1)}\left(\theta_{l_{1}}^{\prime}, \varphi_{l_{1}}^{\prime}\right) \bar{Q}_{l_{2}, k_{l_{2}}}^{(2)}\left(\theta_{l_{2}}^{\prime}, \varphi_{l_{2}}^{\prime}\right)
\end{aligned}
$$


where superscript (1) refers to $\mathrm{D}_{2},(2)$ to X $;\left(R, \Omega_{\mathrm{r}}\right)$ is the vector distance between the two molecules, $\Omega_{\mathrm{r}}$ indicating the orientation of this vector in space-fixed axes $X Y Z ; C$ and $D$ denote the Clebsch-Gordan coefficients and the rotation matrices ; $\Omega_{1}$ and $\Omega_{2}$ represent the set of Euler angles between convenient molecule-fixed axes and $X Y Z$; $\bar{Q}_{l_{i}, k_{i}}^{(i)}\left(\theta_{l_{i}}^{\prime}, \varphi_{l_{i}}^{\prime}\right)$ is the multipole moment of molecule $(i)\left(l_{i}=1\right.$ : dipole moment $; l_{i}=2:$ quadrupole moment...), defined by :

$$
\bar{Q}_{l_{i}, k_{i}}^{(i)}\left(\theta_{l_{i}}^{\prime}, \varphi_{l_{i}}^{\prime}\right)=\sum_{\beta} l_{\beta} r_{\beta}^{l_{i}} Y_{l_{i}, k_{l_{i}}}\left(\theta_{\beta}, \varphi_{\beta}\right)
$$

$\theta_{\beta}$ and $\varphi_{\beta}$ denoting the orientation of the charge $\beta$ in the molecule-fixed axes of molecule (i). It can be shown that, for a diatomic molecule, the non-vanishing terms of $V(t)$ correspond to $k_{l_{2}}=0$.

Thus, neglecting vibration-rotation interaction, as :

$$
\begin{aligned}
\left\langle J_{1}^{\prime} K_{1}^{\prime} M_{1}^{\prime}\left|D_{m_{l_{1}}, k_{1}}^{l_{1}}\left(\Omega_{1}\right)\right| J_{1} K_{1} M_{1}\right\rangle & =\sqrt{\frac{2 J_{1}+1}{2 J_{1}^{\prime}+1}} C\left(J_{1} l_{1} J_{1}^{\prime} \mid K_{1} k_{1} K_{1}^{\prime}\right) C\left(J_{1} l_{1} J_{1}^{\prime} \mid M_{1} m_{l_{1}} M_{1}^{\prime}\right) \\
\left\langle J_{2}^{\prime} M_{2}^{\prime}\left|D_{m_{l_{2}}, 0}^{l_{2}}\left(\Omega_{2}\right)\right| J_{2} M_{2}\right\rangle & =\sqrt{\frac{2 J_{2}+1}{2 J_{2}^{\prime}+1}} C\left(J_{2} l_{2} J_{2}^{\prime} \mid 000\right) C\left(J_{2} l_{2} J_{2}^{\prime} \mid M_{2} m_{l_{2}} M_{2}^{\prime}\right) .
\end{aligned}
$$

We have :

$$
\begin{aligned}
P_{J_{1} J_{2} K_{1} M_{1} M_{2}}^{J_{1}^{\prime} J_{1}^{\prime} M_{2}^{\prime} M_{2}^{\prime}}= & \frac{(4 \pi)^{3}}{\hbar^{2}} \mid \int_{-\infty}^{+\infty} \mathrm{e}^{i \omega t} \sum_{l_{1}, l_{2}} \frac{(-1)^{l_{2}}}{\sqrt{2 l+1}} \sqrt{\frac{(2 l) !}{\left(2 l_{1}+1\right) !\left(2 l_{2}+1\right) !}} R^{-(l+1)} \times \\
& \times \sum_{m_{l_{1}, m_{l_{2}}} \sum_{m_{l_{1}}} C\left(l_{1} l_{2} l \mid m_{l_{1}} m_{l_{2}} m_{l}\right) C\left(J_{1} l_{1} J_{1}^{\prime} \mid K_{1} k_{l_{1}} K_{1}^{\prime}\right) C\left(J_{1} l_{1} J_{1}^{\prime} \mid M_{1} m_{l_{1}} M_{1}^{\prime}\right)} \\
& \times C\left(J_{2} l_{2} J_{2}^{\prime} \mid 000\right) C\left(J_{2} l_{2} J_{2}^{\prime} \mid M_{2} m_{l_{2}} M_{2}^{\prime}\right) \sqrt{\frac{2 J_{1}+1}{2 J_{1}^{\prime}+1} \times \frac{2 J_{2}+1}{2 J_{2}^{\prime}+1}}\left\langle n_{2}\left|\bar{Q}_{l_{2}, 0}^{(2)}\left(\theta_{l_{2}}^{\prime}, \varphi_{l_{2}}^{\prime}\right)\right| n_{2}+1\right\rangle \\
& \times\left.\left\langle n_{1}+1\left|\bar{Q}_{l_{1}, k_{1}}^{(1)}\right| n_{1}\right\rangle \mathrm{d} t\right|^{2} .
\end{aligned}
$$

Following Tsao's way of calculation, [6] assuming straight line trajectories and weighting over initial rotational states by a Maxwell Boltzmann distribution, we finally get :

$$
\begin{aligned}
P_{J_{1} J_{2} K_{1}}^{J_{1}^{\prime} J_{i}^{\prime} K_{1}^{\prime}}=\sum_{l_{1}, l_{2}} \frac{(4 \pi)^{2}}{\left(2 l_{1}+1\right)\left(2 l_{2}+1\right)} \frac{4(2 l) !}{\left(2 l_{1}+1\right) !\left(2 l_{2}+1\right) !} \sum_{k_{l_{1}}}\left|Q_{l_{1}, k_{l_{1}}}\right|^{2}\left|Q_{l_{2}}\right|^{2} \times \\
\quad \times C^{2}\left(J_{1} l_{1} J_{1}^{\prime} \mid K_{1} k_{l_{1}} K_{1}^{\prime}\right) C^{2}\left(J_{2} l_{2} J_{2}^{\prime} \mid 000\right) \frac{G_{l}(\omega b / v)}{\hbar^{2} v^{2} b^{2 l}} P_{J_{1}, K_{1}} P_{J_{2}}
\end{aligned}
$$

$Q_{l_{1}, k_{1}}$ and $Q_{l_{2}}$ being the vibrational multipole matrix elements of molecules (1) and (2), $b$ the impact parameter, $P_{J_{1}, K_{1}}$ and $P_{J_{2}}$ the distribution of rotational populations in the initial states $\left|n_{1} J_{1} K_{1}\right\rangle$ and $\left|n_{2}+1 J_{2}\right\rangle$ and $G_{l}$ the function :

$$
G_{l}(x)=\sum_{\mu=-l}^{l}[(l+\mu) !(l-\mu) !]^{-1} x^{2 l} K_{\mu}^{2}(x)
$$

where $K_{\mu}$ is the modified Bessel function of order $\mu$.

Following Sharma's formulation [2], we can then integrate over $v$, and summing over $J_{1}, K_{1}$ and $J_{2}$ gives :

$$
\begin{aligned}
P=\frac{M}{k T} \sum_{l_{1}, l_{2}} \frac{4(2 l) !}{\left(2 l_{1}+1\right) !\left(2 l_{2}+1\right) !} & \frac{(4 \pi)^{2}}{\left(2 l_{1}+1\right)\left(2 l_{2}+1\right)} \sum_{k_{l_{1}}}\left|Q_{l_{1}, k_{l_{1}}}\right|^{2}\left|Q_{l_{2}}\right|^{2} \times \\
& \times \sum_{\substack{J_{1, J_{2}} \\
K_{1}}} \sum_{\substack{J_{1}, J^{\prime} \\
K_{1}^{\prime}}} C^{2}\left(J_{1} l_{1} J_{1}^{\prime} \mid K_{1} k_{1} K_{1}^{\prime}\right) C^{2}\left(J_{2} l_{2} J_{2}^{\prime} \mid 000\right) \frac{\bar{I}_{l}(b, \omega, T)}{\hbar^{2} b^{2 l}} P_{J_{1}, K_{1}} P_{J_{2}}
\end{aligned}
$$

where $M$ is the reduced mass of the colliding particles, and

$$
\bar{I}_{l}(b, \omega, T)=\frac{M}{2 k T} \int_{0}^{\infty} \frac{1}{v^{2}} G_{l}\left(\frac{\omega b}{v}\right) \exp \left(-\frac{M v^{2}}{2 k T}\right) v^{3} \mathrm{~d} v .
$$

We can finally derive $\langle P\rangle$ by integrating over $b$, following Sharma [2]. 
3. Applications. - We have applied this theory to calculate $\langle P\rangle$ for the following energy-exchange reactions :

$$
\begin{aligned}
\mathrm{D}_{2}(v=1)+\mathrm{CH}_{3} \mathrm{Cl} \leftrightarrows \mathrm{D}_{2}(v=0)+\mathrm{CH}_{3} \mathrm{Cl}\left(v_{1}=1\right)-24.1 \mathrm{~cm}^{-1} \\
\mathrm{D}_{2}(v=1)+\mathrm{CH}_{3} \mathrm{Cl} \leftrightarrows \mathrm{D}_{2}(v=0)+\mathrm{CH}_{3} \mathrm{Cl}\left(v_{4}=1\right)+52 \mathrm{~cm}^{-1} \\
\mathrm{D}_{2}(v=1)+\mathrm{CH}_{3} \mathrm{CCH} \leftrightarrows \mathrm{D}_{2}(v=0)+\mathrm{CH}_{3} \mathrm{CCH}\left(v_{2}=1\right)-60 \mathrm{~cm}^{-1} \\
\mathrm{D}_{2}(v=1)+\mathrm{CH}_{3} \mathrm{CCH} \leftrightarrows \mathrm{D}_{2}(v=0)+\mathrm{CH}_{3} \mathrm{CCH}\left(v_{6}=1\right)-9 \mathrm{~cm}^{-1} \\
\mathrm{D}_{2}(v=1)+\mathrm{NH}_{3} \leftrightarrows \mathrm{D}_{2}(v=0)+\mathrm{NH}_{3}\left(v_{1}=1\right)+346 \mathrm{~cm}^{-1}
\end{aligned}
$$

Reactions (1), (3) and (5) correspond to a parallel band, i.e., $l_{1}=1, l_{2}=2$ and $k_{l_{1}}=0$; reactions (2) and (4) correspond to a perpendicular band, i.e. $l_{1}=1, l_{2}=2$ and $k_{l_{1}}= \pm 1$. We have used the numerical values listed in Table I for the symmetric top molecules, with for $D_{2}: \omega_{e}=3118.5 \mathrm{~cm}^{-1} ; \omega_{\mathrm{e}} x_{\mathrm{e}}=64.1 \mathrm{~cm}^{-1}$; $B=30.43 \mathrm{~cm}^{-1} ;\left|Q_{2}\right|^{2}=1.1 \times 10^{-54}$ e.s.u.

Table I. - Symmetric top molecules : numerical values used in the calculation.

\begin{tabular}{|c|c|c|c|c|c|}
\hline Molecule & $\mathrm{CH}_{3} \mathrm{Cl}$ & $\mathrm{CH}_{3} \mathrm{Cl}$ & $\mathrm{CH}_{3} \mathrm{CCH}$ & $\mathrm{CH}_{3} \mathrm{CCH}$ & $\mathrm{NH}_{3}$ \\
\hline Mode & $v_{1}$ & $v_{4}$ & $v_{2}$ & $v_{6}$ & $v_{1}$ \\
\hline Band centre $\left(\mathrm{cm}^{-1}\right)$ & $2966.2[7]$ & $3041.8[7]$ & $2930[9]$ & $2981[9]$ & $3337[7]$ \\
\hline$A\left(\mathrm{~cm}^{-1}\right)$ & 5.09 & 5.09 & $5.4[10]$ & 5.4 & 6.3 \\
\hline$B\left(\mathrm{~cm}^{-1}\right)$ & 0.49 & 0.49 & 0.285 & 0.285 & 9.94 \\
\hline$\left|Q_{1, l}\right|^{2}$ (e.s.u.) & $3.6 \times 10^{-39}[8]$ & $1.4 \times 10^{-39}[8]$ & $6.1 \times 10^{-39}[9]$ & $5.9 \times 10^{-39}[9]$ & $5.9 \times 10^{-40}[11]$ \\
\hline$\langle P\rangle$ for $T=300 \mathrm{~K}$ & $1 \times 10^{-4}$ & $2.8 \times 10^{-5}$ & $1.5 \times 10^{-5}$ & $3.4 \times 10^{-5}$ & $2.5 \times 10^{-6}$ \\
\hline
\end{tabular}

4. Results. - Figure 1 shows the variations of $\langle P\rangle$, summed over the initial rotational quantum numbers up to $J_{1}=50, J_{2}=10$ and $K_{1}=13$, for $T=200 \mathrm{~K}$ to $1000 \mathrm{~K}$. It can be seen that the transfer probability is quite small as compared for example with $\mathrm{D}_{2}(v=1)-\mathrm{HCl}(v=0) \quad \mathrm{V}-\mathrm{V}$ energy-exchange reaction for which $\langle P\rangle=2.8 \times 10^{-4}$ [12] at $296 \mathrm{~K}$. This is mainly due to the larger number of rotational levels in symmetric top molecules as compared with linear molecules. However, reaction (5) being very off-resonant, the theory must greatly underestimate $\langle P\rangle$. This explains the initial increase of $\langle P\rangle$ for reaction (5), whilst the initial increase for reaction (3) is not clear. Sharma's theory has already given good results for much more off-resonant processes than reaction (3) $(\Delta E / k T=0.43$ for $T=200 \mathrm{~K})$ such as $\mathrm{HCl}-\mathrm{D}_{2}$ energy exchange reaction $(\Delta E / k T=0.78$ for $T=200 \mathrm{~K})$ [12]. The inclusion of quadrupolequadrupole effects, resulting in an increase of $\langle P\rangle$ for low $T$, might suppress this initial increase.

One must also point out that Sharma's theory doesn't satisfy the detailed rate balance, by a factor $\exp \left(-\Delta E_{\mathrm{v}} / k T\right)$, where $\Delta E_{\mathrm{v}}$ is the vibrational energy mismatch. It has sometimes been suggested to multiply $\langle P\rangle$ by $\alpha=\exp \left(-\Delta E_{\mathrm{v}} / 2 k T\right)$, thus leading to the detailed balancing. By the way, for processes (1) to (4), $\alpha$ is close to unity. Only for process (5) is $\alpha$ very different from unity, thus lowering $\langle P\rangle$.

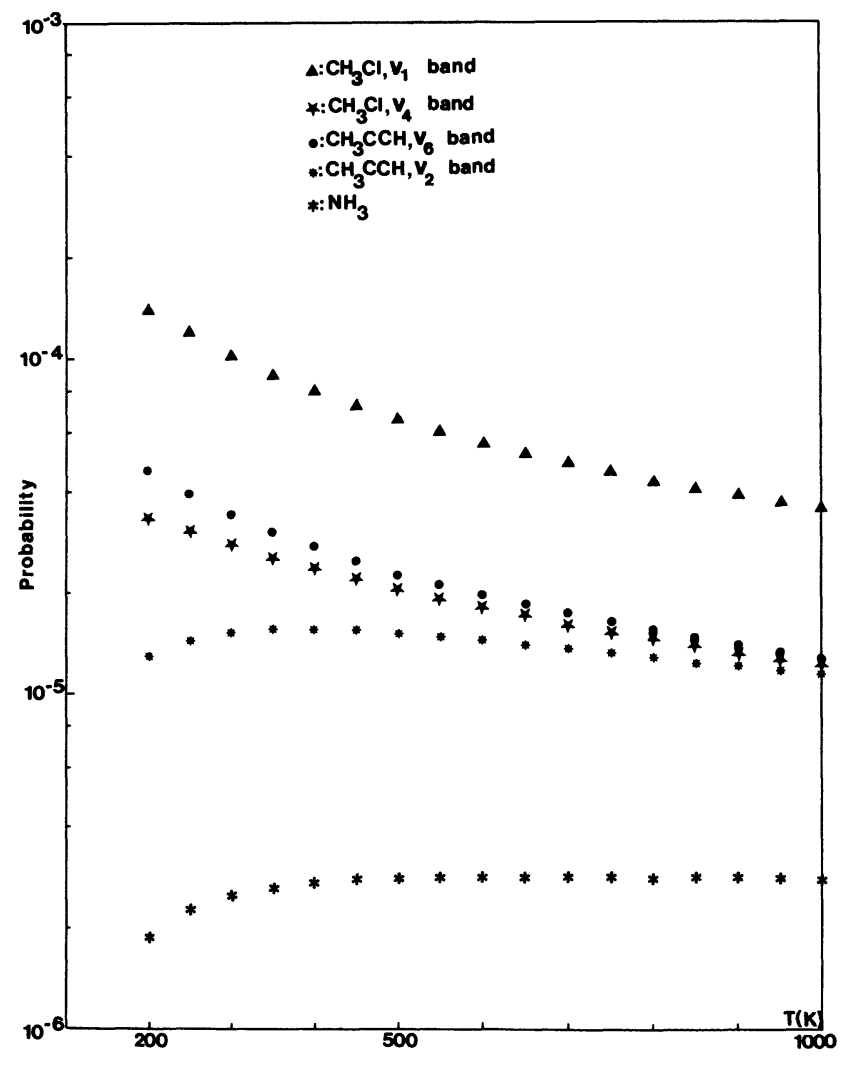

Fig. 1. - V-V energy-exchange probabilities as a function of temperature. 


\section{References}

[1] Sharma, R. D. and Brau, C. A., Phys. Rev. Lett. 19 (1967) 1273.

[2] Sharma, R. D. and Brau, C. A., J. Chem. Phys. 50 (1969) 924.

[3] Preses, J. M. and Flynn, G. W., J. Chem. Phys. 66 (1977) 3112.

[4] Gray, C. G., Can. J. Phys. 46 (1968) 135.

[5] Sharma, R. D. and Picard, R. H., J. Chem. Phys. 62 (1975) 3340.

[6] Tsao, C. J. and Curnutte, B., J. Quant. Spectrosc. Radiat. Transfer 2 (1962) 41.
[7] Herzberg, G., Molecular Spectra and molecular structure, Vol. II (D. van Nostrand Company).

[8] Barrow, G. M. and Mac Kean, D. C., Proc. R. Soc. London A $213(1952) 27$.

[9] Kondo, S. and Koga, Y., J. Chem. Phys. 69 (1978) 4022.

[10] DunCan, J. L., J. Mol. Spectrosc. 46 (1973) 232.

[11] Mac Kean, D. C. et al., J. Chem. Phys. 24 (1956) 316.

[12] Hopkins, B. M., Chen, H. L. and Sharma, R. D., J. Chem. Phys. 59 (1973) 5759. 